\title{
Surface Quality in Milling of AZ91D Magnesium Alloy
}

\author{
Ireneusz Zagórski ${ }^{1 *}$, Jarosław Korpysa² \\ 1 Department of Production Engineering, Mechanical Engineering Faculty, Lublin University of \\ Technology, 36 Nadbystrzycka Str., 20-618 Lublin, Poland \\ 2 Student of Mechanical Engineering Faculty, Lublin University of Technology, ul. Nadbystrzycka 36, \\ 20-618 Lublin, Poland \\ * Corresponding author's e-mail: i.zagorski@pollub.pl
}

\begin{abstract}
This paper is an attempt at determining the effect of technological parameters of milling on the surface roughness of the AZ91D magnesium alloy. The cutting tool used in tests was a TiAlN-coated carbide milling cutter. The milling tests were carried out at variable cutting speed, feed per tooth and depth of cut, and the results were compared. The analysis was based on the 2D roughness parameters measured on the end and lateral faces of specimens, as well as on the 3D roughness parameters measured on the end faces of specimens. The test results indicated that the increase in the feed per tooth results in the increase in the value of $2 \mathrm{D}$ and $3 \mathrm{D}$ surface roughness parameters. It was found that cutting speed and axial depth of cut have a negligible effect on the $2 \mathrm{D}$ roughness of the workpiece surface, whereas the increase in cutting speed results in the reduction of the 3D surface roughness parameters.
\end{abstract}

Keywords: magnesium alloys, surface roughness, high-speed dry milling

\section{INTRODUCTION}

The quality requirements of the surfaces subjected to machining are constantly increasing, particularly in the cases where a good fit of elements is of critical utilitarian importance. As a consequence, the need arises to conduct research that would explore the surface roughness analysis and the impact of the applied cutting data on the condition of the surface, thus leading to establishing an optimal combination of technological parameters and tools. The available scientific literature in the field tends to focus on a single roughness parameter, which is usually the Ra or Rz. Performing measurements of a wider range of $2 \mathrm{D}$ and $3 \mathrm{D}$ surface roughness parameters enables conducting a more detailed characterisation and description of the impact of a particular set of the cutting data on the workpiece surface quality and the mating of elements in joints and connectors $[3,7,15,16]$. In addition to size and shape accuracy, surface quality is among the most frequently analysed machining indicators. One of the effects of machining (e.g. milling or brush treatment) is the modification of surface roughness [8]. Milling, drilling or boring typically constitute the final operation in machining; hence in many cases, in addition to adequate process efficiency and effectiveness, it is also important to properly structure the surface roughness, furthermore accounting for the functional characteristics of a given surface of magnesium alloy workpieces [4].

The study reported in [9] tested the solid carbide end mills with and without TiN and TiAlN coating, which were engaged in machining $\mathrm{SiC}$ and $\mathrm{B}_{4} \mathrm{C}$ reinforced magnesium matrix workpiece material and performed at a spindle speed in the range of $1500-2500 \mathrm{rev} / \mathrm{min}\left(\mathrm{v}_{\mathrm{c}}=19-31 \mathrm{~m} / \mathrm{min}\right)$ and feed per tooth ranged between 1200 and $2000 \mathrm{~mm} / \mathrm{min}$. The study showed the built-up cutting edge and a change in feed per tooth exerted the greatest impact on the roughness of the test workpiece. The optimal surface quality was obtained in the machining carried out by means of a TiN-coated tool, where the value of Ra was equal to $0.35 \mu \mathrm{m}$. In a similar study [14], the authors 
sought an optimal combination of cutting parameters in order to obtain low surface roughness in milling of AM60 magnesium alloy. The machining was performed without the cutting liquid, by means of a TiN-coated carbide milling cutter. The results of the measurements obtained from the study showed several distinguishable correlations: the increase in feed per tooth and axial depth of cut caused the increase in the surface roughness, whereas, at the increased spindle speed, the surface roughness parameters were reduced. It was shown that the optimal cutting data are: spindle speed $2000 \mathrm{rev} / \mathrm{min}$, feed per tooth $0.1 \mathrm{~mm} / \mathrm{rev}$ and axial depth of cut $1.0 \mathrm{~mm}$. Machining performed in accordance with this cutting data produced the optimal surface roughness Ra of approx. $0.3 \mu \mathrm{m}$.

In face milling of AZ61 alloy carried out by means of a cutter tool with carbide insert cutters [1] at a speed of $500-2000 \mathrm{rev} / \mathrm{min}$, the obtained roughness Ra was in the range of $0.115-0.403 \mu \mathrm{m}$. Despite the application of different feed per tooth, the surface roughness was recorded at constantly low values. What follows from the results is that such cutting data enable effective machining while maintaining high-quality surface.

In another study [11], the application of a face milling cutter in high-speed machining (HSM) of AZ91D, operating at small feed per tooth $0.03-0.09 \mathrm{~mm} /$ tooth and axial depth of cut $0.2-0.3 \mathrm{~mm}$, led to obtaining very low surface roughness of the workpiece material $\mathrm{Ra}=0.061-0.133 \mu \mathrm{m}$. In the analysed case, the lowest Ra was achieved at the lowest tested cutting speed variants, i.e. $900 \mathrm{~m} / \mathrm{min}$. The results obtained from the tests showed that owing to the low roughness obtained by milling at high speeds, the need for implementing additional finishing operations, such as grinding or polishing, is eliminated since face milling produces sufficiently highquality surface finish. Similar conclusions may be drawn from the study presented in [6], involving a comparative analysis of the surface roughness of AZ91HP alloy workpieces following different machining treatment. The operations applied to the specimens tested in the study included abrasive cloth treatment with P320 grit fabric, 180 and 240 non-woven fabric tools and a carbide tool. It was demonstrated that the highest-quality surface was measured on the surfaces subjected to milling: $\mathrm{Ra}=0.124 \mu \mathrm{m}$ and $\mathrm{Rz}=0.952 \mu \mathrm{m}$; while the highest roughness values recorded in the study, $\mathrm{Ra}=0.81 \mu \mathrm{m}$ and $\mathrm{Rz}=3.82 \mu \mathrm{m}$, were observed in the surfaces treated with the 180 non-woven tool. The paper also presents the results of 3D surface roughness parameter measurements following abrasive treatment. The highest values of Sa, $\mathrm{Sz}$ and $\mathrm{Sq}$ parameters were similarly measured on the surface treated with 180 non-woven tool, whereas the lowest - on the surface treated with abrasive cloth.

In the work $[2,12,13]$, the study focused on the machinability of biodegradable magnesium alloys from the Mg-Ca group, a typical orthopaedic material. The dry-cutting burnishing was carried out in the $\mathrm{v}_{\mathrm{c}}$ range up to $2800 \mathrm{~m} / \mathrm{min}$ by means of the face milling cutter with PCD cutting inserts. Adjusting cutting speed $\mathrm{v}_{\mathrm{c}}$ resulted in obtaining the surface roughness parameter Ra of approx. $0.5 \mu \mathrm{m}$. A similar relationship was observed by modifying the depth of cut of $a_{p}$; however, the most critical impact on the surface quality was observed in the modification of feed per tooth. In this case, the Ra parameter changed in the range from $0.2 \mu \mathrm{m}$ at feed $\mathrm{f}_{\mathrm{z}}=0.05 \mathrm{~mm} /$ tooth, to $0.78 \mu \mathrm{m}$ at feed $\mathrm{f}_{\mathrm{z}}=0.4 \mathrm{~mm} /$ tooth. Similarly, the work [10] involved assessing the roughness of biodegradable $\mathrm{MgCa} 0.8$ alloys. The machining was executed by means of the face milling cutter with carbide inserts, which was set to operate in the speed range of $500 \div 950 \mathrm{~m} / \mathrm{min}$. Feed per tooth was shown to have a major effect on the Ra parameter, which was in the range of $0.093-1.395 \mu \mathrm{m}$. In comparison, the specimens subjected to burnishing treatment exhibited an increase in roughness from approx. $\mathrm{Ra}=0.4 \mu \mathrm{m}$ (following milling in the speed range of $\mathrm{v}_{\mathrm{c}}=2000-2800 \mathrm{~m} / \mathrm{min}$ ) to approx. $\mathrm{Ra}=0.6 \mu \mathrm{m}($ at $\mathrm{F}=400-800 \mathrm{~N})$.

The paper [5] reports the surface roughness measurements performed in AZ31B alloy milling with compressed air acting as a coolant. The face milling cutter with carbide inserts was the employed as a cutting tool in the tests which set out to determine the effect of the coolant feed angle, the number of cutting edges $(z=1-6)$ and the effect of cutting data on the surface roughness (e.g. $\mathrm{v}_{\mathrm{c}}$ up to $311 \mathrm{~m} / \mathrm{min}$ ). The increase in surface roughness was observed to be the result of an increase in feed per tooth and in the number of cutting edges. However, in the applied range of cutting speeds, the roughness remained largely unaffected, although it did respond positively to the introduction of the compressed air cooling. Similarly, in [17], a modular milling cutter with uncoated solid carbide cutters was applied in down milling tests under dry conditions; the absence of coolant was to facilitate chip collection. The machining 
was carried out at conventional cutting parameters, maximum $\mathrm{v}_{\mathrm{c}}=400 \mathrm{~m} / \mathrm{min}$. In the analysed study, the roughness (represented by Ra parameter) increases with the rise in both $\mathrm{v}_{\mathrm{c}}$ and $\mathrm{f}_{\mathrm{z}}$. An alternative method for the assessment of surface quality is based on the size and quality of chips: proper chip morphology indicates high-quality surface finish. AZ91D alloy tests showed that the chip quality depends on feed per tooth, while cutting speed affects its morphology. The lowest roughness, i.e. $\mathrm{Ra}=0.5 \mu \mathrm{m}$, was obtained while implementing low cutting speed $\mathrm{v}_{\mathrm{c}}=50 \mathrm{~m} / \mathrm{min}$ and low feed per tooth $\mathrm{f}_{\mathrm{z}}=0.2 \mathrm{~mm} /$ tooth. It was observed that roughness increased along with cutting speed - as a consequence of the "softening" effect of the material at high temperature; it can also lead to the formation of built-up cutting edge, resulting in the deterioration in the quality of the machined surface.

The study presented in [4] investigated magnesium alloy AZ91HP workpiece surface roughness following machining as a function of change of technological parameters $\left(\mathrm{v}_{\mathrm{c}}, \mathrm{f}_{\mathrm{z}}, \mathrm{a}_{\mathrm{p}}\right)$ and cutting edge geometry $\left(\gamma=5^{\circ}\right.$ and $\left.\gamma=30^{\circ}\right)$. The tests used carbide cutters. The roughness measurements were carried out on the end and lateral faces of the test specimens. The results from the lateral face measurements indicated a decrease in roughness parameters in response to the increase in $\mathrm{v}_{\mathrm{c}}$, and their the increase along with the increase in $\mathrm{f}_{\mathrm{z}}$.
A similar relationship was observed on the end face of Mg alloy specimens. Finally, lower values of roughness parameters were recorded while using a tool inclined at an angle $\gamma=5^{\circ}$.

In addition, the surface roughness analysis is a key indicator for a range of other machining processes: from pre-treatment, e.g. plastic forming, to preliminary preparation of semi-finished products for further processing, e.g. using the AWJM method [18], and brush treatment (edge deburring) [8] there is a need for a broader description of the surface finish quality of workpieces. In the vast majority of the analysed literature, descriptions mainly pertain to the basic Ra roughness parameter; this seems to be highly insufficient given the utilitarian characteristics of magnesium alloy workpiece surfaces.

\section{OBJECTIVES AND METHODOLOGY OF THE STUDY}

The aim of the conducted works was to analyse the effect of technological parameters on the $2 \mathrm{D}$ and $3 \mathrm{D}$ surface roughness parameters of AZ91D magnesium alloy. The research plan for the analysis of the impact of selected factors on the surface roughness is presented in Figure 1.

Milling was carried out by means of a vertical milling centre VMC $800 \mathrm{HS}$ provided by AVIA

a)

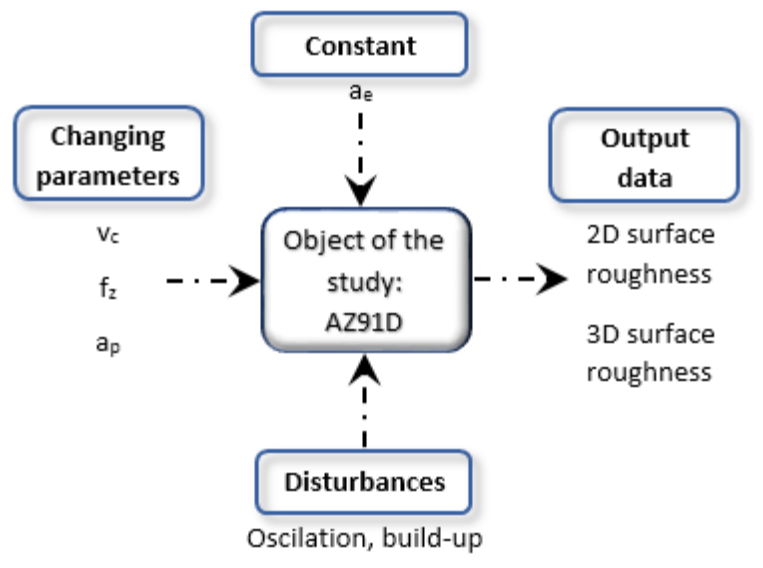

b)

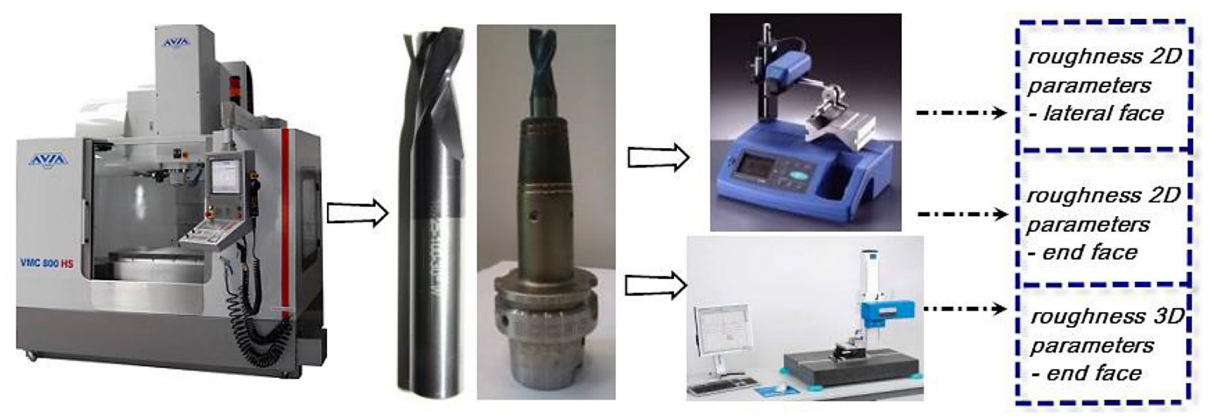

Fig. 1. Surface roughness test plan: a) process data, b) experimental set-up 
with Heidenhain iTNC 530 control system. The tool used during machining was the Ø16 twoedge TiAlN-coated carbide cutter from the family of VHM cutters provided by Fenes. As far as the milling cutting data are concerned, the technological process was performed at the following ranges: cutting speed $\mathrm{v}_{\mathrm{c}}=400-1200 \mathrm{~m} / \mathrm{min}$, feed per tooth $\mathrm{f}_{\mathrm{z}}=0.05-0.30 \mathrm{~mm} /$ tooth, axial depth of cut $a_{p}=0.5-6 \mathrm{~mm}$; the constant parameter of machining was radial depth of cut $\mathrm{a}_{\mathrm{e}}=14 \mathrm{~mm}$. The $2 \mathrm{D}$ roughness measurements conducted on the end and lateral faces of specimens were carried out in five repetitions on each surface with a Hommel Tester T1000 contact profilometer equipped with phase-correct profile filter M1, according to EN ISO 11562 (measurement parameters: traverse length $1 \mathrm{t}=4.8 \mathrm{~mm}$ and sampling length $\ln =0.8 \mathrm{~mm}$, scan rate $\mathrm{v}_{\mathrm{t}}=0.5 \mathrm{~mm} / \mathrm{s}$, measuring ranges/resolution $M= \pm 320 \mu \mathrm{m} / 0.04 \mu \mathrm{m}$ ). The $3 \mathrm{D}$ roughness contour measurement was performed on end faces of specimens with T8000 RC120-400 device by Hommel Etamic. The measurements of roughness parameters were carried out in the direction perpendicular to the lay of machining marks. The scanning area of surface samples was $1.6 \times 1.6 \mathrm{~mm}$ with 100 scanning step.

For maximum stability, the cutter was mounted in the HSK-A63 tool holder. The tool with the Seco - Tools SFD 16x120 holder was balanced to ISO G2.5 balance grade in accordance with ISO 21940-11: 2016. The measured residual unbalance value amounted to $0.87 \mathrm{gmm}$ (the measurement was performed by means of CIMAT RT 610 balancing machine).

\section{RESULTS AND ANALYSIS}

The results from tests and measurements are presented in the form of bar charts with the indication of standard deviation as a measure of scatter of results. Figures $2-16$ show 2D roughness parameters and include their average values (the average of five measurements for given processing parameters). The analysed $3 \mathrm{D}$ roughness parameters (Figures 17-31) were collected in one roughness map (for each set of parameters); therefore, the graphs do not contain standard deviation. For the sake of a more detailed analysis, the statistical parameters of surface roughness Rsk and Rku (skewness, kurtosis) were employed to provide more specific data regarding the profile asymmetry and profile's coefficient of skewness; an additional statistical test for identification and rejection of outliers (Dixon's Q test) was performed.

Figure 2 shows the values of $\mathrm{Rv}, \mathrm{Rp}$ and Rt measured on the end and lateral faces over changing cutting speed $v_{c}$. The values of $R v$ and $\mathrm{Rp}$ on the end face of specimens are similar and in the range of $6.8-8.32 \mu \mathrm{m}$, while on lateral faces 1.22-2.94 $\mu \mathrm{m}$. The Rt parameter amounts to $14.24-17.72 \mu \mathrm{m}$ on the end faces and $3.08-4.8 \mu \mathrm{m}$ on the lateral faces. No significant effect of increasing cutting speed on the value of the measured roughness parameters $\mathrm{Rv}, \mathrm{Rp}$ and Rt was observed.

The effect of the change in cutting speed $\mathrm{V}_{\mathrm{c}}$ on the value of parameter $\mathrm{Ra}$ is shown in Figure 3. Notably, the end faces exhibited several times higher values of the said parameter than the lateral faces; however, they never exceeded $3.12 \mu \mathrm{m}$. The roughness on the lateral faces was approx. $0.616 \mu \mathrm{m}$.

Figure 4 shows the influence of cutting speed $\mathrm{V}_{\mathrm{c}}$ change on the value of Rku parameter. Lower values of the parameter $(<3)$ were obtained on the end face. This stems from the fact that these

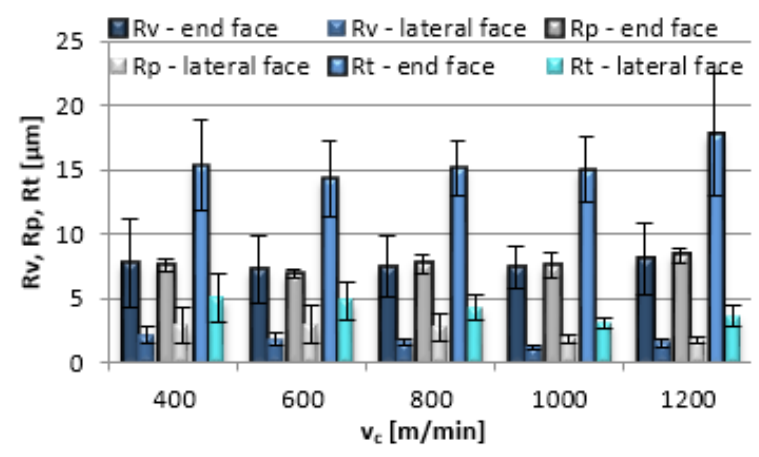

Fig. 2. Effect of cutting speed $v_{c}$ change on $\mathrm{Rv}, \mathrm{Rp}, \operatorname{Rt}\left(\mathrm{f}_{\mathrm{z}}=0.15 \mathrm{~mm} /\right.$ tooth, $\left.\mathrm{a}_{\mathrm{p}}=6 \mathrm{~mm}\right)$

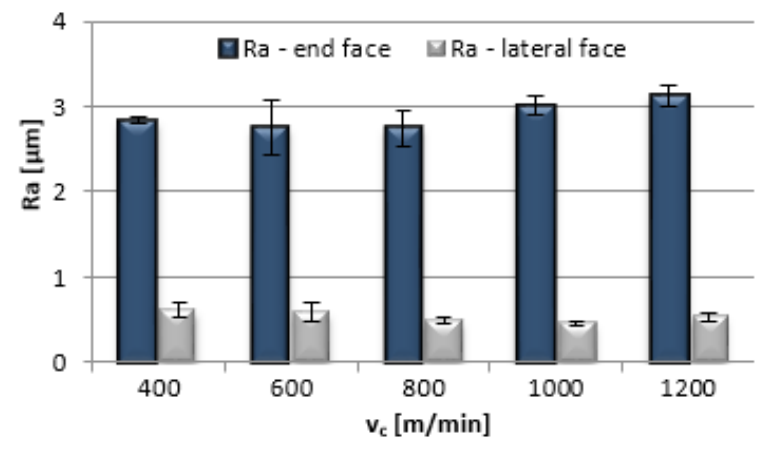

Fig. 3. Effect of cutting speed $v_{c}$ change on $\mathrm{Ra}\left(\mathrm{f}_{\mathrm{z}}=0.15 \mathrm{~mm} /\right.$ tooth, $\left.\mathrm{a}_{\mathrm{p}}=6 \mathrm{~mm}\right)$ 


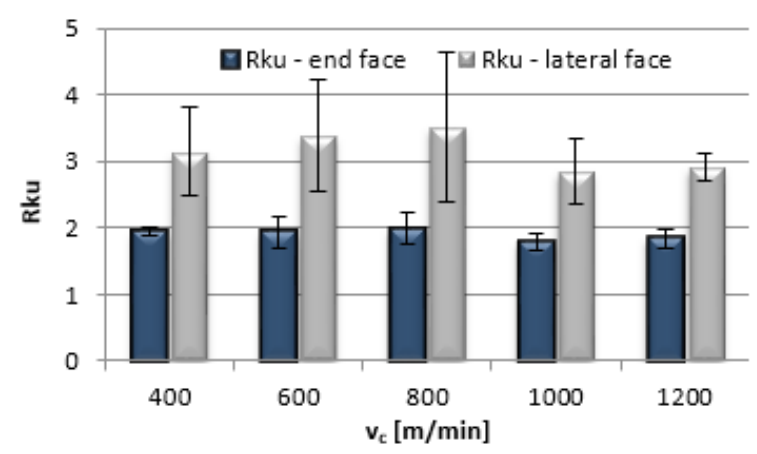

Fig. 4. Effect of cutting speed $\mathrm{v}_{\mathrm{c}}$ change on $\mathrm{Rku}\left(\mathrm{f}_{\mathrm{z}}=0.15 \mathrm{~mm} /\right.$ tooth, $\left.\mathrm{a}_{\mathrm{p}}=6 \mathrm{~mm}\right)$

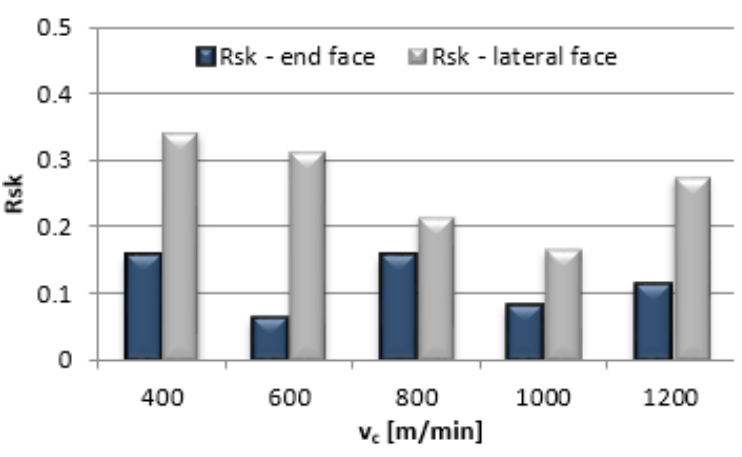

Fig. 5. Effect of cutting speed $\mathrm{v}_{\mathrm{c}}$ change on Rsk $\left(\mathrm{f}_{\mathrm{z}}=0.15 \mathrm{~mm} /\right.$ tooth, $\left.\mathrm{a}_{\mathrm{p}}=6 \mathrm{~mm}\right)$

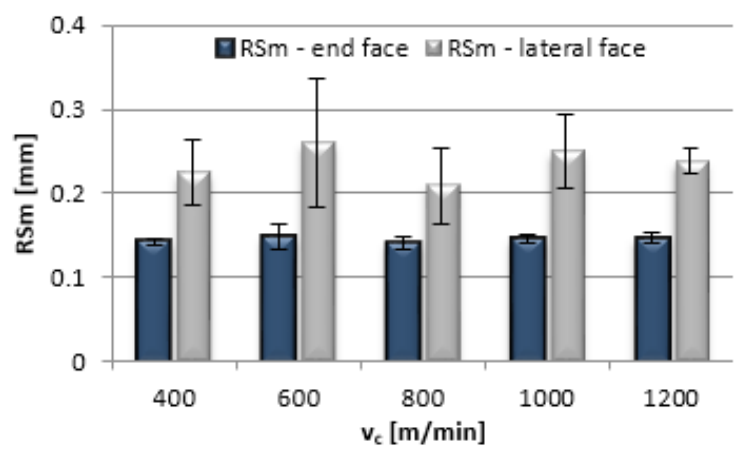

Fig. 6. Effect of cutting speed $v_{c}$ change on $\operatorname{RSm}\left(\mathrm{f}_{\mathrm{z}}=0.15 \mathrm{~mm} /\right.$ tooth, $\left.\mathrm{a}_{\mathrm{p}}=6 \mathrm{~mm}\right)$

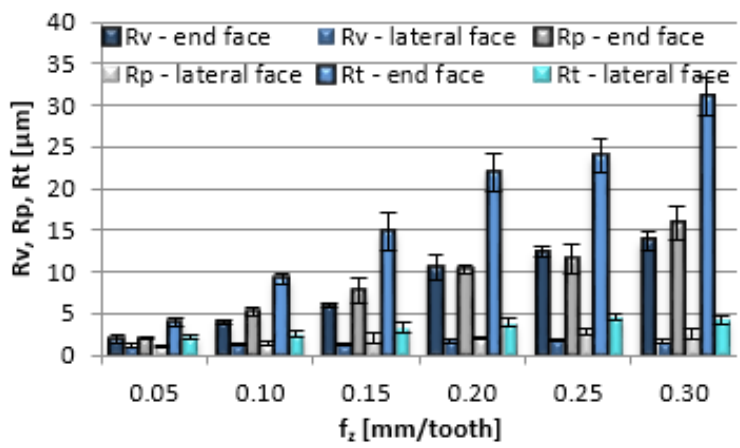

Fig. 7. Effect of feed per tooth $f_{z}$ change on $\operatorname{Rv}, \operatorname{Rp}, \operatorname{Rt}\left(\mathrm{v}_{\mathrm{c}}=800 \mathrm{~m} / \mathrm{min}, \mathrm{a}_{\mathrm{p}}=6 \mathrm{~mm}\right)$ surfaces are characterised by more rounded corners, which results in the increase in the friction coefficient. On the lateral face, the specimens exhibited higher values $(>3)$, which is typical of the surfaces with a large number of sharp peaks, which in the case of surface mating would result in the reduced friction.

The values of Rsk measured at variable cutting speed $v_{c}$ are shown in Figure 5. The values on the end face are low, approximate to the normal distribution, while on the lateral face, the values in question do not exceed 0.2.

Figure 6 shows the values of RSm obtained from the measurements under variable cutting speed $\mathrm{v}_{\mathrm{c}}$. On the end face of the workpiece, the average value of RSm was approx. $0.14 \mathrm{~mm}$ for the entire cutting speed range, and on the lateral face $0.29-0.26 \mathrm{~mm}$.

Figure 7 presents the measured values of $\mathrm{Rv}, \mathrm{Rp}$ and $\mathrm{Rt}$ on the end and lateral faces. The increase in feed per tooth $f_{z}$ resulted in an increase in roughness parameters on both the face and lateral faces. The Rv and Rp parameters are between 1.94 and $15.84 \mu \mathrm{m}$ on the end face of test specimens and between 1.08 and $2.76 \mu \mathrm{m}$ on the lateral face. The Rt parameter amounts to $4-31.04 \mu \mathrm{m}$ on the end faces, while on lateral faces it is $2.24-4.48 \mu \mathrm{m}$.

Figure 8 presents the change in the values of $R a$ in variable feed per tooth $f_{z}$ scenario. Significantly lower values were obtained on the lateral faces, and their increase was not as marked as in the case of the end faces - for which the values of $0.53-5.62 \mu \mathrm{m}$ were obtained.

Figure 9 shows the impact of increasing feed per tooth $\mathrm{f}_{\mathrm{z}}$ on the obtained values of Rku. Lower values ( $\mathrm{Rku}<3$ ), resulting in an increased coefficient of friction, were recorded on the end face of specimens. On the lateral faces, the values oscillated in the vicinity of $\mathrm{Rku}=3$, hence leading to the distribution being close to normal. With the increase of $f_{z}, R k u$ decreases on the lateral faces (up to about 2.5) and then stabilizes on the workpiece end face (up to approx. 2).

Figure 10 shows the effect of feed per tooth $\mathrm{f}_{\mathrm{z}}$ on Rsk. The value of skewness on the machined end faces takes positive as well as negative values. Positive values were obtained on the lateral faces, which indicates higher corrosion resistance as well as an increased coefficient of friction.

The values of RSm obtained in the conditions of changing feed per tooth are shown in Figure 11. Increasing the feed per tooth resulted 


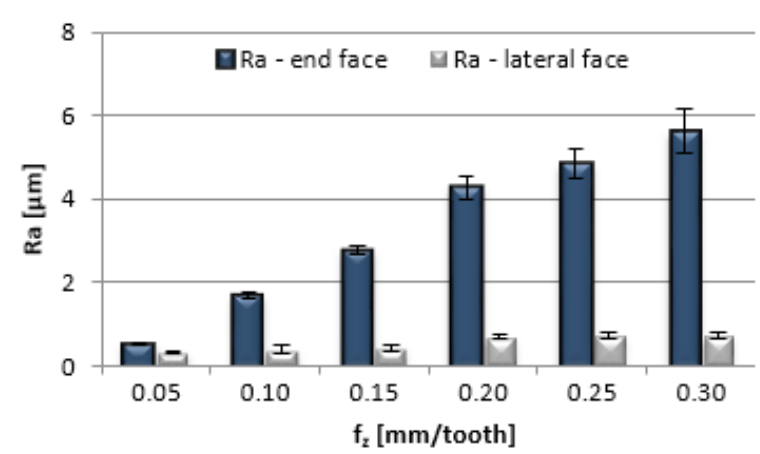

Fig. 8. Effect of feed per tooth $\mathrm{f}_{\mathrm{z}}$ change on $\mathrm{Ra}\left(\mathrm{v}_{\mathrm{c}}=800 \mathrm{~m} / \mathrm{min}, \mathrm{a}_{\mathrm{p}}=6 \mathrm{~mm}\right)$

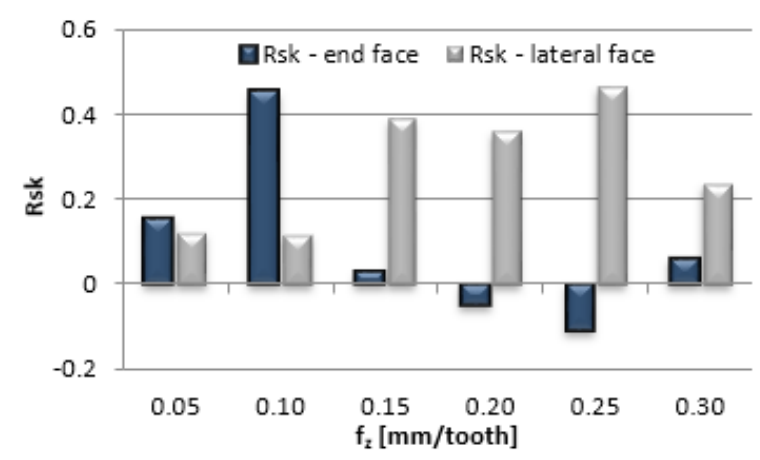

Fig. 10. Effect of feed per tooth $\mathrm{f}_{\mathrm{z}}$ change on Rsk ( $\left.v_{c}=800 \mathrm{~m} / \mathrm{min}, a_{p}=6 \mathrm{~mm}\right)$

in an increase in RSm on the machined end and lateral faces; however, lower average values in the range $0.096-0.264 \mathrm{~mm}$ were obtained on the end face of specimens.

Figure 12 shows the values of $\mathrm{Rv}, \mathrm{Rp}$ and $\mathrm{Rt}$ obtained during machining at variable axial depth of cut $\mathrm{a}_{\mathrm{p}}$. For $\mathrm{Rv}$ and $\mathrm{Rp}$, similar values were obtained in the range of $5.26-7.78 \mu \mathrm{m}$, whereas for Rt - 12.02-24.82 $\mu \mathrm{m}$.

Figure 13 shows the values of Ra reflecting the change in axial depth of cut a during machining: the average values of $\mathrm{Ra}$ increased slightly

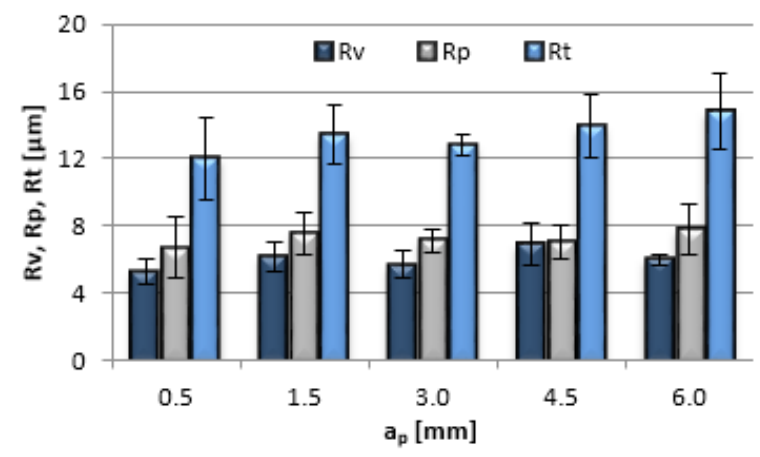

Fig. 12. Effect of axial depth of cut $a_{p}$ change on $\mathrm{Rv}, \operatorname{Rp}, \operatorname{Rt}\left(\mathrm{v}_{\mathrm{c}}=800 \mathrm{~m} / \mathrm{min}, \mathrm{f}_{\mathrm{z}}=0.15^{\mathrm{p}} \mathrm{mm} /\right.$ tooth$)$

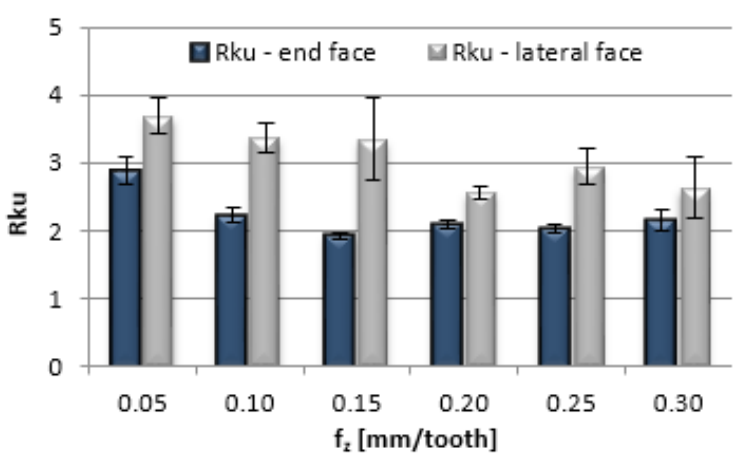

Fig. 9. Effect of feed per tooth $f_{z}$ change on $\mathrm{Rku}\left(\mathrm{v}_{\mathrm{c}}=800 \mathrm{~m} / \mathrm{min}, \mathrm{a}_{\mathrm{p}}=6 \mathrm{~mm}\right)$

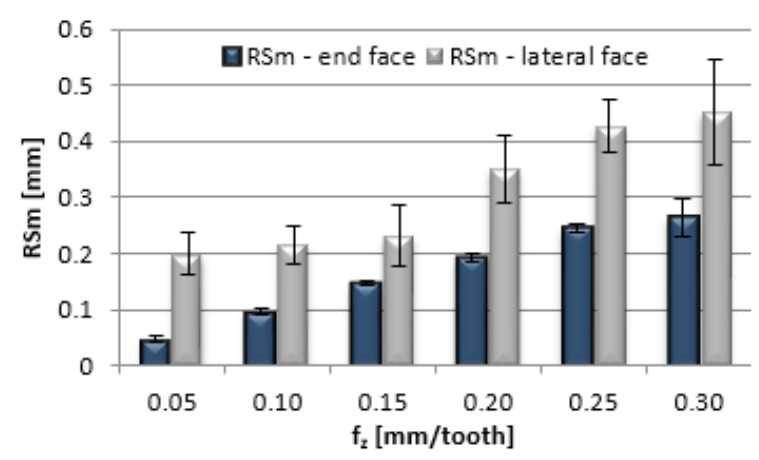

Fig. 11. Effect of feed per tooth $\mathrm{f}_{\mathrm{z}}$ change on $\operatorname{RSm}\left(\mathrm{v}_{\mathrm{c}}=800 \mathrm{~m} / \mathrm{min}, \mathrm{a}_{\mathrm{p}}=6 \mathrm{~mm}\right)$

and ranged from 2.35 to $2.90 \mu \mathrm{m}$. This observation indicates that there is a distinct possibility of efficient and effective milling of AZ91D magnesium alloy without significant deterioration of the workpiece surface roughness (which is in this case defined by Ra). A negligible scatter of results in the range of $a_{p}=3-6 \mathrm{~mm}$ points at better repeatability and stability of the process, in comparison to, e.g. machining at $\mathrm{a}_{\mathrm{p}}=0.5 \mathrm{~mm}$. In addition, machining with a slight allowance is not recommended for the economic reasons and safety of dry milling of magnesium alloys.

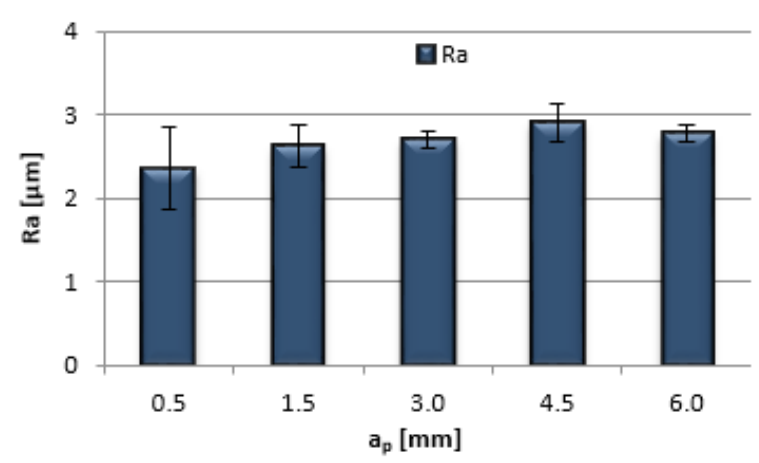

Fig. 13. Effect of axial depth of cut $a_{p}$ change on $\operatorname{Ra}\left(\mathrm{v}_{\mathrm{c}}=800 \mathrm{~m} / \mathrm{min}, \mathrm{f}_{\mathrm{z}}=0.15 \mathrm{~mm} /\right.$ tooth $)$ 
Figure 14 shows the values of Rku measured on the end face of specimens. Values below 3 are characteristic of the surfaces with rounded peaks, which additionally increases the coefficient of friction.

Figure 15 shows values of Rsk at changing depth of cut $a_{p}$. Small values indicate an approximately symmetrical distribution of peaks and valleys.

The recorded values of RSm for variable axial depth of cut $a_{p}$ are shown in Figure 16. It was shown that the change in axial depth of cut has a negligible effect on average values of RSm, which were in the range $0.137-0.151 \mathrm{~mm}$.

The influence of cutting speed $\mathrm{v}_{\mathrm{c}}$ on the surface roughness parameters $\mathrm{Sv}, \mathrm{Sp}$ and $\mathrm{St}$ on the workpiece end faces is shown in Figure 17. The parameter values decreased when cutting speed increased. The $\mathrm{Sv}$ and $\mathrm{Sp}$ values were in the range of $6.1-12.1 \mu \mathrm{m}$, while the parameter St reached 24-14.4 $\mu \mathrm{m}$.

Figure 18 shows the effect of axial depth of cut $\mathrm{a}_{\mathrm{p}}$ on $\mathrm{Sa}$. In the entire cutting speed range, similar values were obtained, and their values were within the range of $2.55-2.74 \mu \mathrm{m}$.

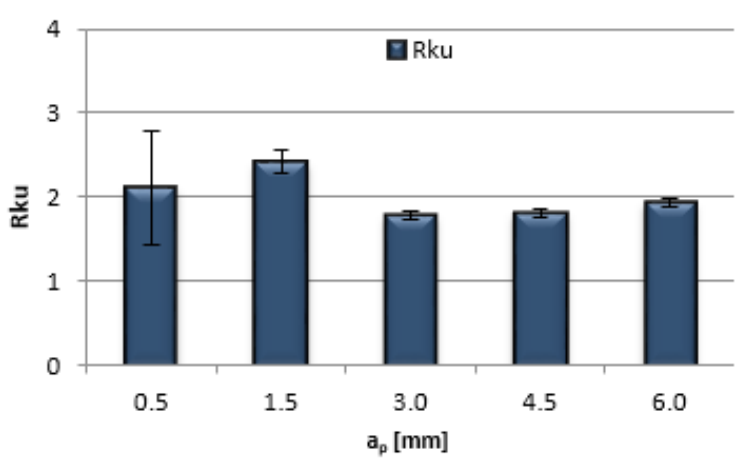

Fig. 14. Effect of axial depth of cut $\mathrm{a}_{\mathrm{p}}$ change on $\mathrm{Rku}\left(\mathrm{v}_{\mathrm{c}}=800 \mathrm{~m} / \mathrm{min}, \mathrm{f}_{\mathrm{z}}=0.15 \mathrm{~mm} /\right.$ tooth $)$

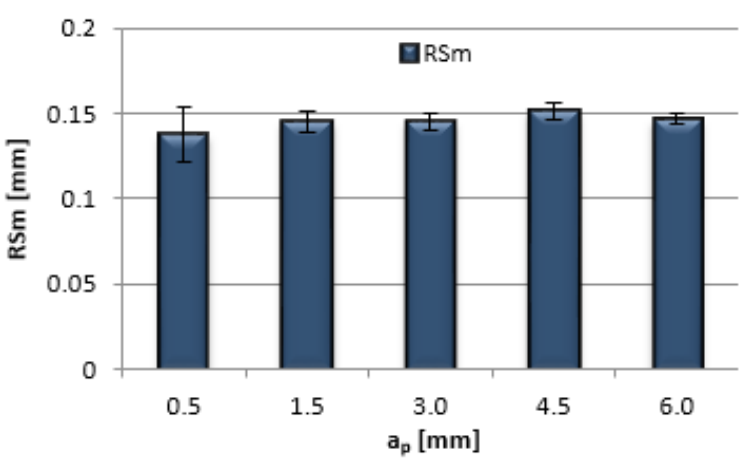

Fig. 16. Effect of axial depth of cut a change on $\operatorname{RSm}\left(\mathrm{v}_{\mathrm{c}}=800 \mathrm{~m} / \mathrm{min}, \mathrm{f}_{\mathrm{z}}=0.15 \mathrm{~mm} /\right.$ tooth $)$
The values of Sku parameter shown in Figure 19 reflect the change in cutting speed $\mathrm{v}_{\mathrm{c}}$. The obtained parameter values were less than 3 , regardless of the change in the parameter in question. There is also a slight decrease in the value of Sku, as well as the increase in cutting speed $\mathrm{v}_{\mathrm{c}}$. The response observed in the tests may be considered a beneficial effect of employing high cutting speeds, defined as HSM.

Figure 20 shows the values of Ssk obtained from measurements on the end face of specimens. Low and positive values indicate an approximately symmetrical distribution of peaks and valleys, albeit, slightly below the average. Such a distribution characterises surfaces exhibiting higher corrosion resistance.

Figure 21 shows the effect of feed per tooth $\mathrm{f}_{\mathrm{z}}$ change on the obtained values of Sv, Sp and St. Increasing the feed per tooth significantly influenced the Sp parameter, the values of which are in the range of $6.12-11.3 \mu \mathrm{m}$ and as a result of which the values of the St parameter - 15.5-21.1 $\mu \mathrm{m}$ also changed. The value of the Sv parameter was below $10 \mu \mathrm{m}$ in the entire range of the feed per tooth change.

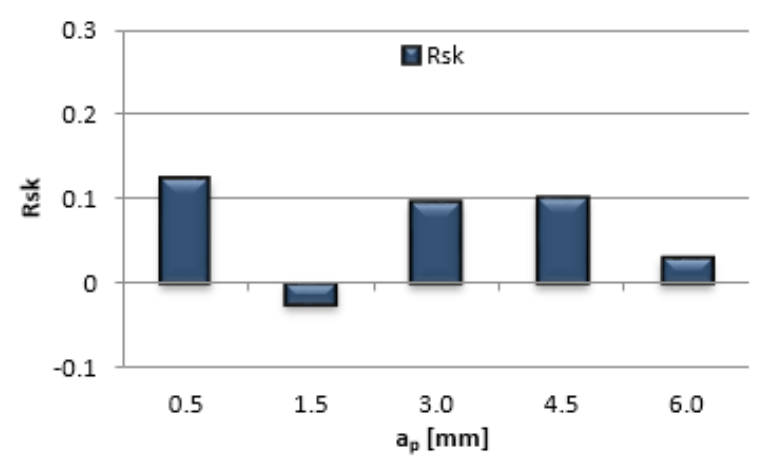

Fig. 15. Effect of axial depth of cut $a_{p}$ change on Rsk ( $\mathrm{v}_{\mathrm{c}}=800 \mathrm{~m} / \mathrm{min}, \mathrm{f}_{\mathrm{z}}=0.15 \mathrm{~mm} /$ tooth $)$

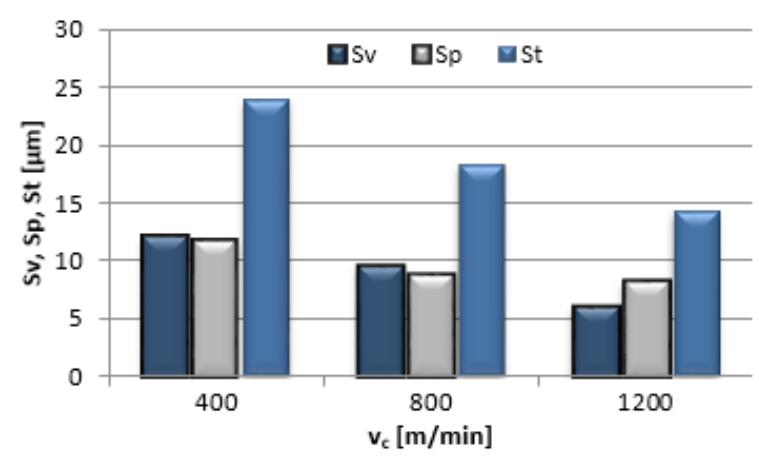

Fig. 17. Effect of cutting speed $v_{c}$ change on $\mathrm{Sv}, \mathrm{Sp}, \mathrm{St}\left(\mathrm{f}_{\mathrm{z}}=0.15 \mathrm{~mm} /\right.$ tooth, $\left.\mathrm{a}_{\mathrm{p}}=6 \mathrm{~mm}\right)$ 


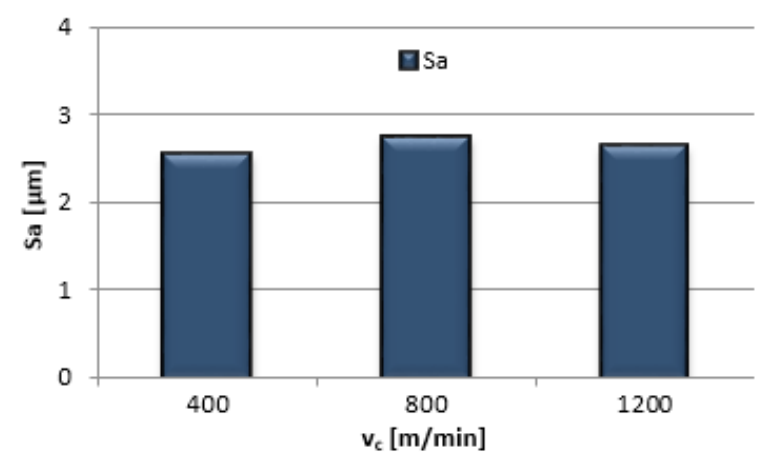

Fig. 18. Effect of cutting speed $v_{c}$ change on $\mathrm{Sa}\left(\mathrm{f}_{\mathrm{z}}=0.15 \mathrm{~mm} /\right.$ tooth, $\left.\mathrm{a}_{\mathrm{p}}=6 \mathrm{~mm}\right)$

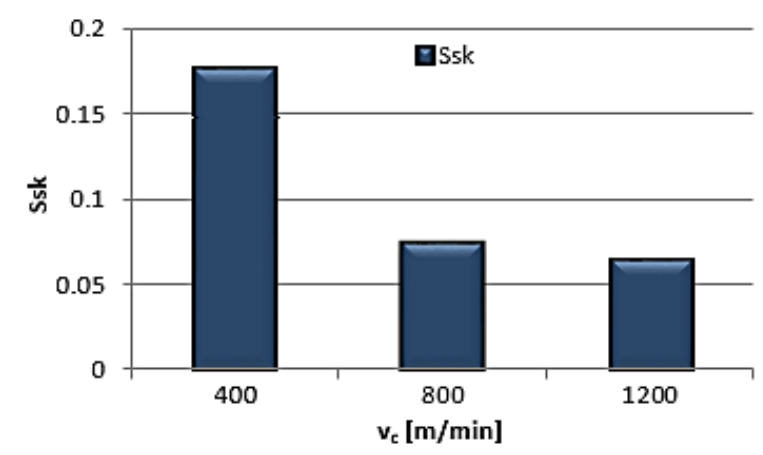

Fig. 20. Effect of cutting speed $v_{c}$ change on Ssk $\left(f_{z}=0.15 \mathrm{~mm} /\right.$ tooth, $\left.a_{p}=6 \mathrm{~mm}\right)$

Figure 22 shows the impact of feed per tooth $\mathrm{f}_{\mathrm{z}}$ on Sa. Increasing the feed rate $f_{z}$ caused a severalfold increase in the parameter value from $0.54 \mu \mathrm{m}$ to $4.26 \mu \mathrm{m}$. The values of the Sku parameter obtained under variable feed per tooth $\mathrm{f}_{\mathrm{z}}$ are shown in Figure 23. As a result of the feed per tooth increase, the value of kurtosis dropped significantly below 3 . As a consequence, the coefficient of friction of the treated surfaces increased. The effect of the feed change $f_{z}$ on the value of the Ssk parameter is shown in Figure 24. The positive skewness values obtained in measurements characteristically

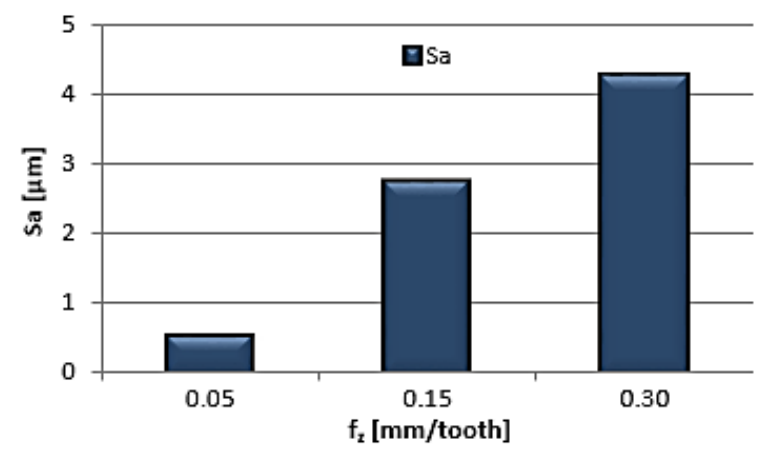

Fig. 22. Effect of feed per tooth $\mathrm{fz}$ change on $\mathrm{Sa}(\mathrm{vc}=800 \mathrm{~m} / \mathrm{min}, \mathrm{ap}=6 \mathrm{~mm})$

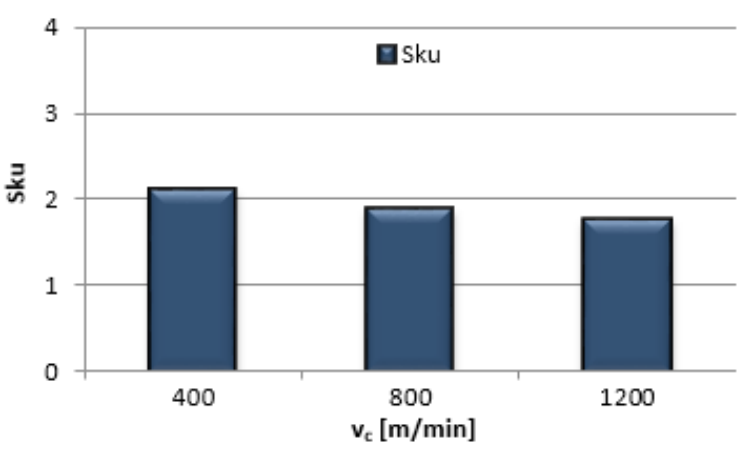

Fig. 19. Effect of cutting speed $v_{c}$ change on Sku $\left(\mathrm{f}_{\mathrm{z}}=0.15 \mathrm{~mm} /\right.$ tooth, $\left.\mathrm{a}_{\mathrm{p}}=6 \mathrm{~mm}\right)$

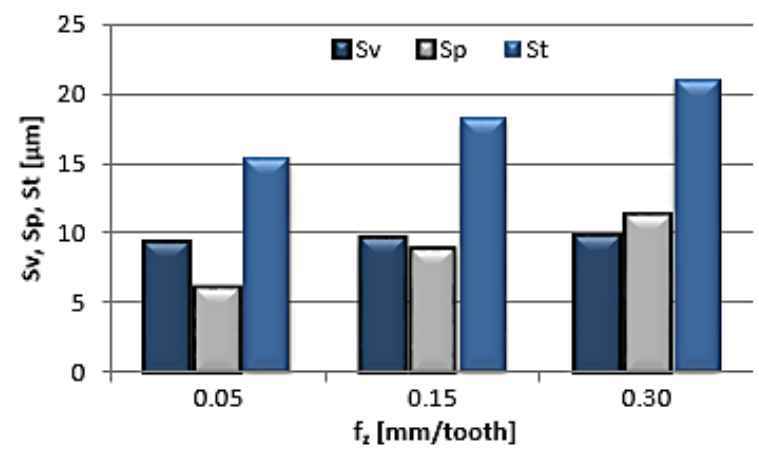

Fig. 21. Effect of feed per tooth $f_{z}$ change on $\mathrm{Sv}, \mathrm{Sp}, \mathrm{St}\left(\mathrm{v}_{\mathrm{c}}=800 \mathrm{~m} / \mathrm{min}, \mathrm{a}_{\mathrm{p}}=6 \mathrm{~mm}\right)$

distributed peaks and valleys below average. The surfaces produced in this way are more resistant to corrosion, but their coefficient of friction is greater. Figure 25 shows the effect of changing axial depth of cut $\mathrm{a}_{\mathrm{p}}$ on the obtained values of Sv, Sp and St. As a consequence, the value of $\mathrm{Sv}$ decreased in the range of 5.79-22.2 $\mu \mathrm{m}, \mathrm{Sp}-5.83-9.78 \mu \mathrm{m}$ and $\mathrm{St}-11.6-31.4 \mu \mathrm{m}$. Figure 26 shows the effect of increasing axial depth of cut $a_{p}$ on the obtained values of $\mathrm{Sa}$, which in these particular conditions, typically, did not significantly affect the obtained values - recorded in the range $2.42-2.79 \mu \mathrm{m}$.

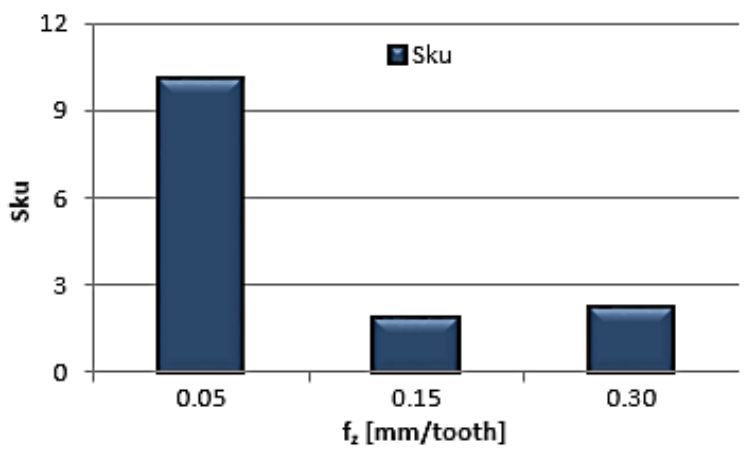

Fig. 23. Effect of feed per tooth $\mathrm{f}_{\mathrm{z}}$ change on Sku $\left(v_{c}=800 \mathrm{~m} / \mathrm{min}, \mathrm{a}_{\mathrm{p}}=6 \mathrm{~mm}\right)$ 


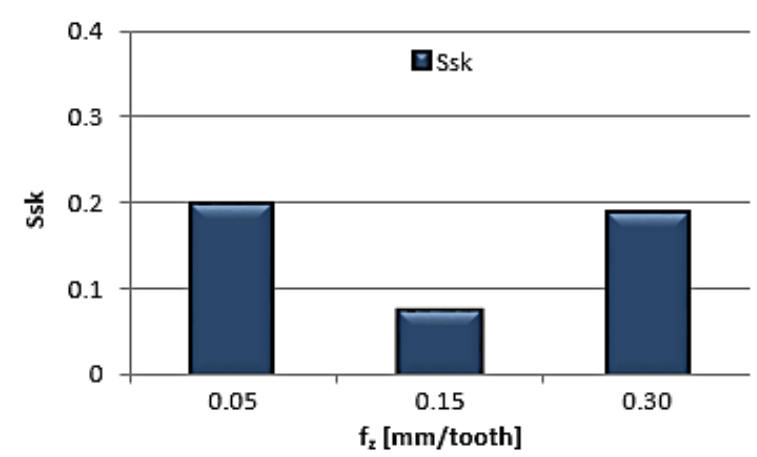

Fig. 24. Effect of feed per tooth $\mathrm{f}_{\mathrm{z}}$ change on Ssk $\left(\mathrm{v}_{\mathrm{c}}=800 \mathrm{~m} / \mathrm{min}, \mathrm{a}_{\mathrm{p}}=6 \mathrm{~mm}\right)$

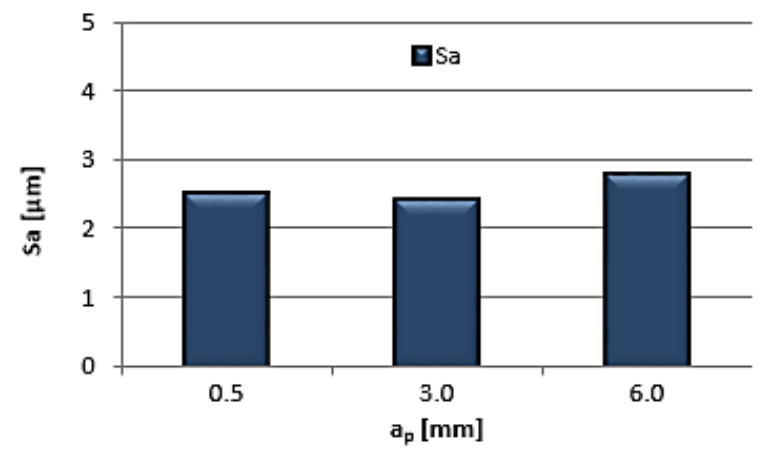

Fig. 26. Effect of axial depth of cut $a_{p}$ change on $\mathrm{Sa}\left(\mathrm{v}_{\mathrm{c}}=800 \mathrm{~m} / \mathrm{min}, \mathrm{f}_{\mathrm{z}}=0.15 \mathrm{~mm} /\right.$ tooth $)$

The influence of modified axial depth of cut $\mathrm{a}_{\mathrm{p}}$ on the values of Sku is shown in Figure 27. In the whole range of changes in axial depth of cut, the parameter values decreased and remained below 3 .

Figure 28 shows the impact of axial depth of cut $a_{p}$ on the Ssk. The obtained skewness values were positive, which indicates surfaces of a slightly increased coefficient of friction. Figure 29 shows the machined surface topography maps for the lowest and highest cutting speeds: $\mathrm{v}_{\mathrm{c}}=400 \mathrm{~m} / \mathrm{min}$ and $\mathrm{v}_{\mathrm{c}}=1200 \mathrm{~m} / \mathrm{min}$. Increasing the cutting speed resulted in a more even distribution of valleys and peaks in relation to the average line. This is a consequence of the decrease in Sku and of the Ssk parameter value approaching zero - normal distribution.

Figure 30 shows the surface topography maps of the workpiece end face machined at the lowest and highest feed per tooth: $\mathrm{f}_{\mathrm{z}}=0.05 \mathrm{~mm} /$ tooth and $\mathrm{f}_{\mathrm{z}}=0.30 \mathrm{~mm} /$ tooth. Increasing feed rate $\mathrm{f}_{\mathrm{z}}$ resulted in a significant increase in surface roughness. The observed result was the shift from a significant number of low peaks to a smaller number of higher peaks, which is associated with a significant decrease in the value of Sku and increase in $\mathrm{Sa}, \mathrm{Sv}, \mathrm{Sp}$, St.

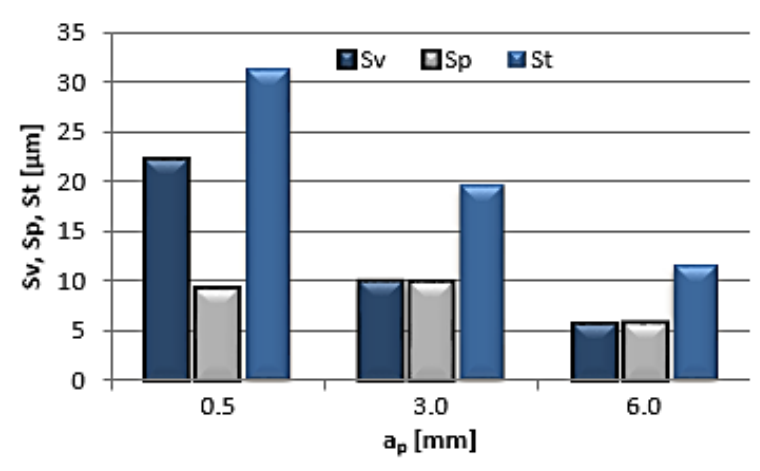

Fig. 25. Effect of axial depth of cut $a_{p}$ change on $\mathrm{Sv}, \mathrm{Sp}, \mathrm{St}\left(\mathrm{v}_{\mathrm{c}}=800 \mathrm{~m} / \mathrm{min}, \mathrm{f}_{\mathrm{z}}=0.15 \mathrm{~mm} /\right.$ tooth$)$

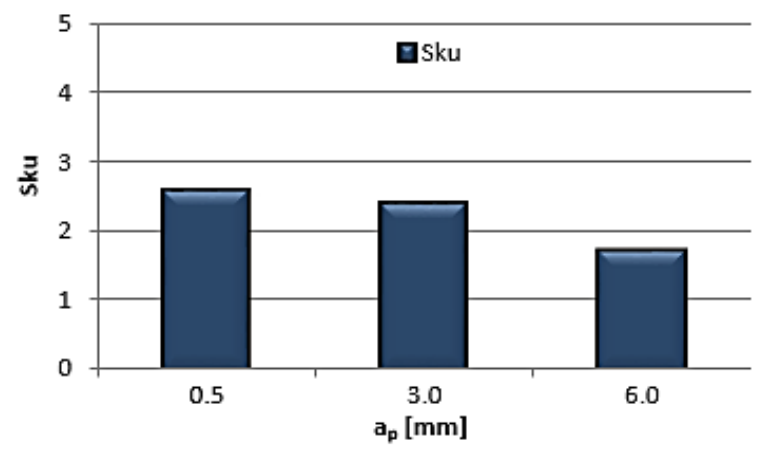

Fig. 27. Effect of axial depth of cut $a_{p}$ change on $\mathrm{Sku}\left(\mathrm{v}_{\mathrm{c}}=800 \mathrm{~m} / \mathrm{min}, \mathrm{f}_{\mathrm{z}}=0.15 \mathrm{~mm} /\right.$ tooth $)$

Figure 31 shows surface topography maps of the workpiece end face machined at the lowest and highest axial depth of cut $a_{p}=0.5 \mathrm{~mm}$ and $a_{p}=6 \mathrm{~mm}$. Increasing axial depth of cut led to the emergence of rounded peaks and valleys with a close to symmetrical distribution relative to the average line. This is the consequence of the decreasing value of Sku and the near-zero value of Ssk.

The above maps of surface topography display the changes that occur on the machined surfaces as a result of the changes in technological milling data.

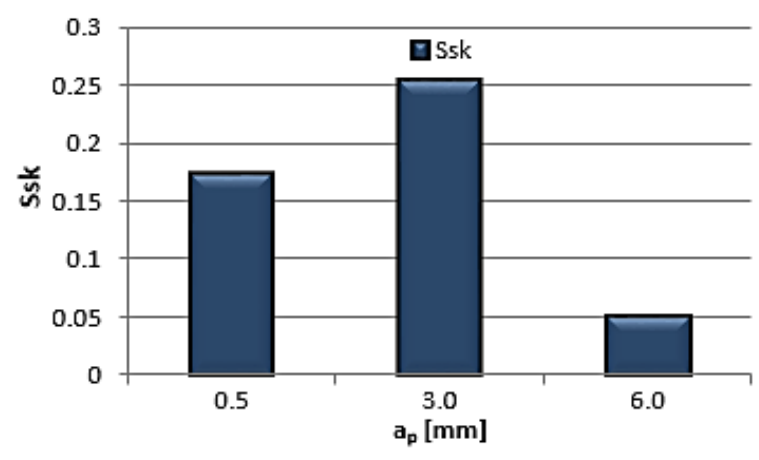

Fig. 28. Effect of axial depth of cut $a_{p}$ change on Ssk $\left(\mathrm{v}_{\mathrm{c}}=800 \mathrm{~m} / \mathrm{min}, \mathrm{f}_{\mathrm{z}}=0.15 \mathrm{~mm} /\right.$ tooth $)$ 
a)

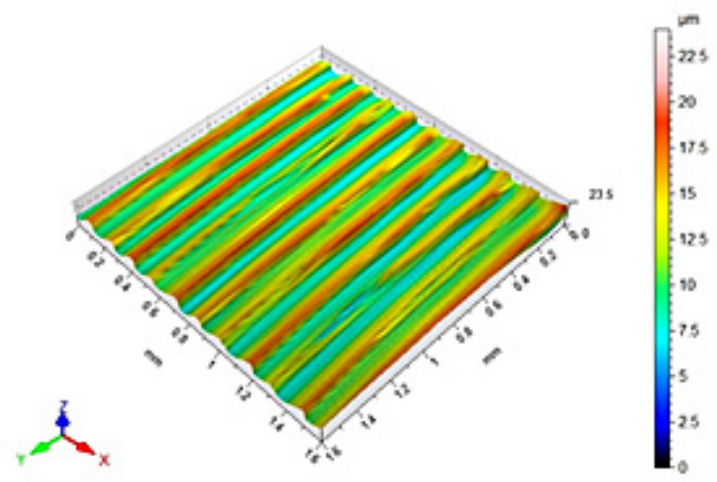

b)

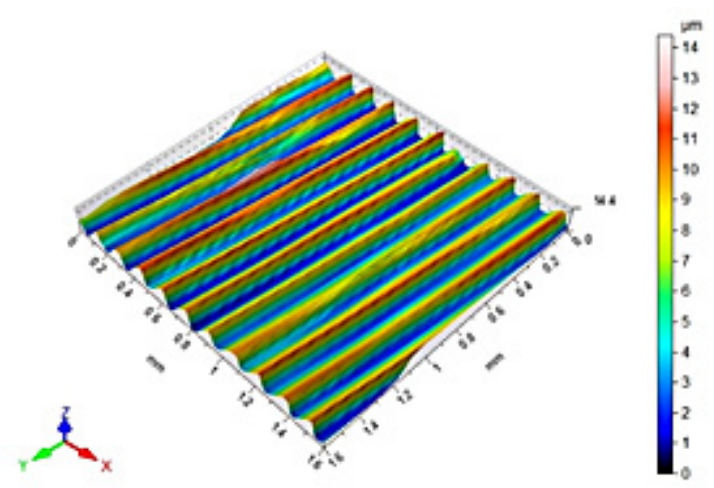

Fig. 29. Specimen surface topography maps machined at variable feed per tooth: a) $\mathrm{f}_{\mathrm{z}}=0.05 \mathrm{~mm} /$ tooth, b) $\mathrm{f}_{\mathrm{z}}=0.30 \mathrm{~mm} /$ tooth $\left(\mathrm{v}_{\mathrm{c}}=800 \mathrm{~m} / \mathrm{min}, \mathrm{a}_{\mathrm{p}}=6 \mathrm{~mm}\right)$

a)

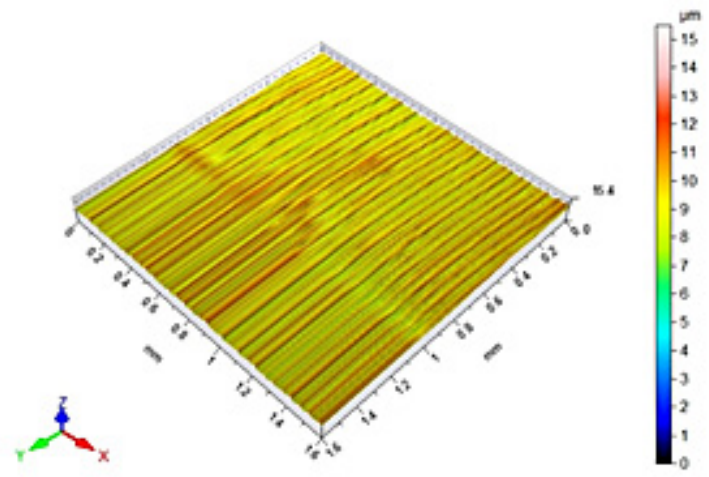

b)

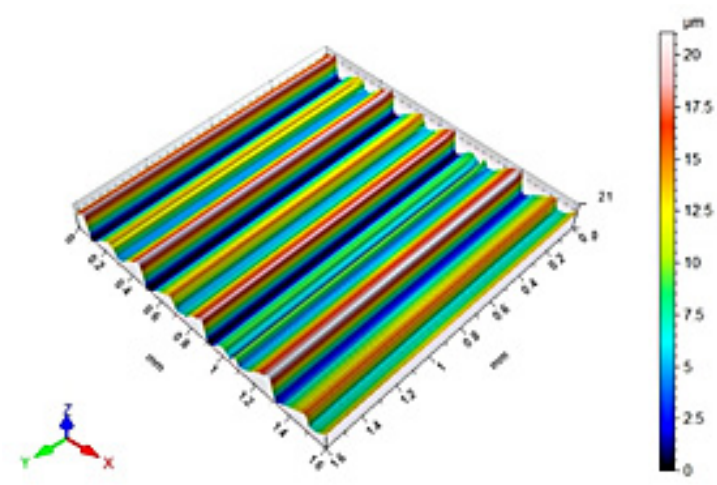

Fig. 30. Specimen surface topography maps machined at variable feed per tooth: a) $\mathrm{f}_{\mathrm{z}}=0.05 \mathrm{~mm} /$ tooth, b) $\mathrm{f}_{\mathrm{z}}=0.30 \mathrm{~mm} /$ tooth $\left(\mathrm{v}_{\mathrm{c}}=800 \mathrm{~m} / \mathrm{min}, \mathrm{a}_{\mathrm{p}}=6 \mathrm{~mm}\right)$

a)

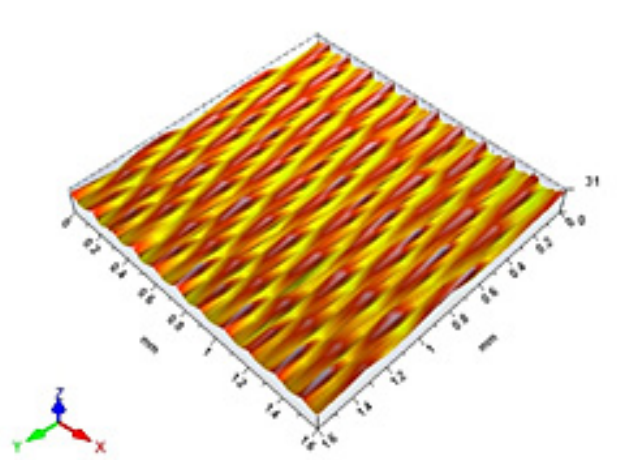

b)

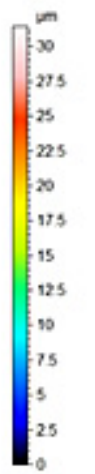

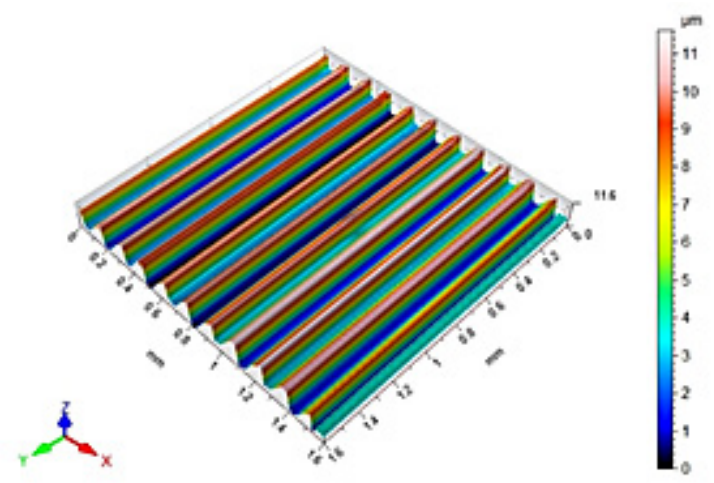

Fig. 31. Specimen surface topography maps machined at variable axial depth of cut: a) $\left.\mathrm{a}_{\mathrm{p}}=0.5 \mathrm{~mm}, \mathrm{~b}\right) \mathrm{a}_{\mathrm{p}}=6 \mathrm{~mm}\left(\mathrm{v}_{\mathrm{c}}=800 \mathrm{~m} / \mathrm{min}, \mathrm{f}_{\mathrm{z}}=0.15 \mathrm{~mm} /\right.$ tooth $)$

\section{CONCLUSIONS}

Based on the experimental tests carried out in the study, the following conclusions were drawn:

- high-quality surface finish can be obtained in milling, through appropriate selection of technological parameters of machining,
- among the analysed milling data, feed per tooth $\mathrm{f}_{\mathrm{z}}$ has the greatest impact, because its increase causes the increase in 2D and 3D surface roughness parameters,

- cutting speed $\mathrm{v}_{c}$ does not significantly affect the $2 \mathrm{D}$ surface roughness of the end and lateral faces of the workpiece, 
- lower values of 3D surface roughness parameters were obtained at a higher cutting speed $\left(\mathrm{v}_{\mathrm{c}}=1200 \mathrm{~m} / \mathrm{min}\right)$,

- axial depth of cut $a_{p}$ has no significant effect on 2D surface roughness parameters on either the end or lateral faces of the workpiece,

- increasing axial depth of cut $a_{p}$ causes the decrease in the values of certain 3D surface roughness parameters,

- negligible effect of axial depth of cut $a_{p}$ on the obtained surface roughness parameters is conducive to increasing the process efficiency while ensuring no significant deterioration of surface finish.

\section{REFERENCES}

1. Alharti N.H., Bingol S., Abbas A.T., Ragab A.E., El-Danaf E.A., Alharbi H.F.: Optimizing Cutting Conditions and Prediction of Surface Roughness in Face Milling of AZ61 Using Regression Analysis and Artificial Neural Network, Advances in Materials Science and Engineering, Vol. 2017, 2017, 1-8.

2. Guo Y.B., Salahshoor M.: Process mechanics and surface integrity by high-speed dry milling of biodegradable magnesium-calcium implant alloys, CIRP Annals - Manufacturing Technology, 59, 2010, 151-154.

3. Grzesik W.: Surface Topography and Utilitarian Characteristics of Machine Parts, Mechanik 8-9, 2015, 587-593.

4. Gziut O., Kuczmaszewski J., Zagórski I.: Surface quality assessment following high performance cutting of AZ91HP magnesium alloy, Management and Production Engineering Review, 6(1), 2015, 4-9.

5. Kim J.D., Lee K.B.: Surface Roughness Evaluation in Dry-Cutting of Magnesium Alloy by Air Pressure Coolant, Engineering, 2, 2010, 788-792.

6. KuczmaszewskiJ.,Pieśko P.,Zawada-Michałowska M.: Surface roughness of thin-walled components made of aluminium alloy EN AW-2024 following different milling strategies, 10(30), 2016, 150-158.

7. Kwiatkowski M.P., Kłonica M., Kuczmaszewski J., Satoh S.: Comparative analysis of energetic properties of Ti6Al4V titanium and EN-AW2017A(PA6) aluminum alloy surface layers for an adhesive bonding application, Ozone: Science \& Engineering: The Journal of the International Ozone Association, 35(3), 2013, 220-228.
8. Matuszak, J., Zaleski, K., Analysis of deburring effectiveness and surface layer properties around edges of workpieces made of 7075 aluminium alloy, Aircraft Engineering and Aerospace Technology, 90(3), 2018, 515-523.

9. Muralidharan S., Karthikeyan N., Kumar A.B., Aatthisugan I.: A study on machinability characteristic in end milling of magnesium composite, International Journal of Mechanical Engineering and Technology, 8(6), 2017, 455-462.

10. Qiao Y., Wang S., Guo P., Yang X., Wang Y.: Experimental research on surface roughness of milling medical magnesium alloy, IOP Conference Series: Materials Science and Engineering, 397(1), 2018, 1-7.

11. Ruslan M.S., Othman K., Ghani J.A., Kassim M.S., Haron C.H.C.: Surface roughness of magnesium alloy AZ91D in high speed milling, Jurnal Teknologi, 78(6-9), 2016, 115-119.

12. Salahshoor M., Guo Y.B.: Cutting mechanics in high speed dry machining of biomedical magnesium-calcium alloy using internal state variable plasticity model, International Journal of Machine Tools \& Manufacture, 51, 2011, 579-590.

13. Salahshoor M., Guo Y.B.: Surface integrity of magnesium-calcium implants processed by synergistic dry cutting-finish burnishing, Procedia Engineering, 19, 2011, 288-293.

14. Sathyamoorthy V., Deepan S., Sathya Prasanth S.P., Prabhu L.: Optimization of Machining Parameters for Surface Roughness in End Milling of Magnesium AM60 Alloy, Indian Journal of Science and Technology, 10(32), 2017, 1-7.

15. Sedlaček M., Vilhena L.M., Podgornik B., Vižintin J.: Surface Topography Modelling for Reduced Friction, Strojniški vestnik - Journal of Mechanical Engineering, 57(9), 2011, 674-680.

16. Sedlaček M., Gregorčič P., Podgornik B.: Use of the Roughness Parameters $S_{s k}$ and $S_{k u}$ to Control Friction - A Method for Designing Surface Texturing, Tribology Transactions, 60(2), 2017, 260-266.

17. Shi K., Zhang D., Ren J., Yao C., Huang X.: Effect of cutting parameters on machinability characteristics in milling of magnesium alloy with carbide tool, Advances in Mechanical Engineering, 8(1), 2016, 1-9.

18. Zagórski, I., Kłonica, M., Kulisz, M., Łoza, K. Effect of the AWJM Method on the Machined Surface Layer of AZ91D Magnesium Alloy and Simulation of Roughness Parameters Using Neural Networks, Materials, 11(11), 2018, 1-18. 